\title{
Pengenalan Rumah Adat di Pulau Jawa Sebagai Media Pembelajaran Berbasis VRML
}

\author{
Ari Fitriyanto $^{1)}$, Kodrat Iman Satoto ${ }^{2)}$, Kurniawan Teguh Martono ${ }^{2)}$ \\ Jurusan Sistem Komputer, Fakultas Teknik, Universitas Diponegoro \\ J1. Prof. Sudharto, Tembalang, Semarang, Indonesia \\ Email: arifitriyanto37@gmail.com
}

\begin{abstract}
Indonesia is rich in culture, ethnicity which one example is the traditional houses that exist in each province. Introduce Indonesian traditional house to users by using information technology as a medium of information could be one way to preserve the nation's culture. Limitations of the media information about traditional houses that currently can only be enjoyed through pictures or visit the traditional houses directly make society can not know the traditional houses in Indonesia optimally. Therefore we need a media so that people can know more about traditional houses in Indonesia without the need to visit directly into sites or less information such as 2-dimensional images in the book.
\end{abstract}

Application developed is combination between virtual reality and website. Application built using the waterfall method. The virtual technology is embedded in a website that allows users to access them anytime and anywhere. Aplication was developed using VRML (Virtual Reality Modeling Language) and 3ds Max modeling software, and using the programming language PHP, HTML, CSS, and MySQL database. The browser needs Cortona3D Viewer plug-in for displaying three-dimensional file.

The results of making this application is an application that utilizes the VRML technology to display traditional house on the island of Java in three dimensions. The results show that this application runs in accordance with the design functionality that has been made.

Keywords : Traditional house, Virtual Reality, VRML, Website, PHP, HTML, CSS, MySQL, Cortona3D Viewer

\section{Pendahuluan}

$\mathrm{I}$ ndonesia yang kaya akan budaya, suku bangsa yang salah satu contohnya adalah rumah adat yang ada di tiap provinsi. Mengenalkan rumah adat Indonesia kepada pengguna dengan menggunakan teknologi informasi sebagai media informasi bisa menjadi salah satu cara untuk menjaga kelestarian budaya bangsa. Keterbatasan media informasi tentang rumah adat yang saat ini hanya dapat dinikmati melalui gambar atau mengunjungi rumah adat secara langsung membuat masyarakat belum bisa mengenal rumah adat di
Indonesia secara optimal. Oleh karena itu diperlukan suatu media agar masyarakat dapat mengenal lebih jauh tentang rumah adat di Indonesia tanpa perlu melihat langsung ke lokasi rumah adat ataupun informasi yang kurang maksimal seperti gambar 2 dimensi pada buku.

\section{LANDASAN TEORI}

\section{A. VRML (Virtual Reality Modelling Language)}

VRML (Virtual Reality Modelling Language) merupakan sebuah bahasa pemrograman yang diciptakan khusus untuk membuat objek-objek 3D. Objek-objek yang dibuat dengan VRML akan memiliki tiga buah dimensi panjang, lebar dan kedalaman, sehingga dapat dipandang dari setiap sudut.

VRML memiliki beberapa kelebihan yang membuatnya banyak digunakan untuk membuat dunia tiga dimensi. Diantaranya adalah :

a. Bahasanya Mudah dan Sederhana

Bahasa VRML sangat mudah digunakan. Struktur dan perintah-perintahnya yang sederhana dapat dipelajari dengan cepat.

b. Cepat

User dapat lebih cepat membuat objek 3D yang sederhana. Jika ada perubahan pada dunia 3D, kita dapat melakukannya dengan cepat tanpa harus mendesain ulang seluruh objek.

c. Fleksibel

Objek 3D yang dibuat dengan VRML dapat ditampilkan pada hampir semua browser. Selain itu format file VRML juga dapat dengan mudah dikonversi ke dalam format-format file 3D lainnya.

d. Dinamis

Kita bisa membuat dunia 3D yang dinamis dan realtime.

e. Interaktif

VRML memiliki beberapa perintah untuk membuat suatu webpage yang tiga dimensi sekaligus interaktif. Dengan cara ini, kita bisa membuat link yang menghubungkan satu dunia VRML dengan dunia VRML lainnya

\section{B. Model Waterfall}

Model SDLC air terjun (waterfall) sering juga disebut model sekuensial linier (sequential linear) atau alur hidup klasik (classic life cycle). Model air terjun menyediakan pendekatan alur hidup perangkat 
lunak secara sekuensial atau terurut dimulai dari analisis, desain, pengodean, pengujian, dan tahap pendukung (support).

Kenyataannya sangat jarang model air terjun dapat dilakukan sesuai alurnya karena sebab sebagai berikut

a. Perubahan spesifikasi perangkat lunak terjadi di tengah alur pengembangan.

b. Sangat sulit bagi pelanggan untuk mendefinisikan semua spesifikasi di awal alur pengembangan. Pelanggan sering kali butuh contoh (prototype) untuk menjabarkan spesifikasi kebutuhan sistem lebih lanjut.

c. Pelanggan tidak mungkin bersabar mengakomodasi perubahan yang diperlukan di akhir alur pengembangan.

Model ini sangat cocok digunakan kebutuhan pelanggan sudah sangat dipahami dan kemungkinan terjadinya perubahan kebutuhan selama pengembangan perangkat lunak kecil. Hal positif dari model air terjun adalah struktur tahap pengembangan sistem jelas, dokumentasi dihasilkan di setiap tahap pengembangan, dan sebuah tahap dijalankan setelah tahap sebelumnya selesai dijalankan (tidak ada tumpang tindih pelaksanaan tahap).

\section{ERD}

Pemodelan awal basis data yang paling banyak digunakan adalah menggunakan Entity Relationship Diagram (ERD). ERD dikembangkan berdasarkan teori himpunan dalam bidang matematika. ERD digunakan untuk pemodelan basis data relasional. Sehingga jika penyimpanan basis data menggunakan OODBMS maka perancangan basis data tidak perlu menggunakan ERD.

\section{D. $P H P$}

PHP merupakan singkatan dari Hypertext Preprocessor yang merupakan bahasa berbentuk skrip yang ditempatkan pada server dan diproses di server. Hasilnya kemudian dikirimkan ke browser klien.

\section{E. Javasript}

Javascript adalah bahasa yang berbentuk kumpulan skrip yang pada fungsinya berjalan pada suatu dokumen HTML. Sepanjang sejarah internet bahasa ini adalah bahasa skrip pertama untuk web. Bahasa ini adalah bahasa pemrograman untuk memberikan kemampuan tambahan terhadap HTML dengan mengijinkan pengeksekusian perintah-perintah di sisi klien, yang artinya di sisi browser bukan di sisi server.

\section{F. MySQL}

MySQL adalah sebuah perangkat lunak sistem manajemen basis data SQL atau DBMS yang multithread, multi-user dengan sekitar 6 juta instalasi di seluruh dunia. MySQL $A B$ membuat $M y S Q L$ tersedia sebagai perangkat lunak gratis di bawah lisensi $G N U$ General Public Licence (GPL). Tetapi mereka juga menjual di bawah lisensi komersial untuk kasus-kasus di mana penggunaannya tida cocok dengan pengunaan GPL.
G. DFD(Data Flow Diagram $)$

Data Flow Diagram (DFD) atau dalam bahasa Indonesia menjadi Diagram Alir Data (DAD) adalah representasi grafik yang menggambarkan aliran informasi dan transformasi informasi yang diaplikasikan sebagai data yang mengalir dari masukan (input) dan keluaran (output).

DFD dapat digunakan untuk merepresentasikan sebuah system atau perangkat lunak pada beberapa level abstraksi. DFD dapat dibagi menjadi beberapa level yang lebih detail untuk merepresentasikan aliran informasi atau fungsi yang lebih detail. DFD menyediakan mekanisme untuk pemodelan fungsional ataupun pemodelan aliran informasi. Oleh karena itu, DFD lebih sesuai digunakan untuk memodelkan fungsifungsi perangkat lunak yang akan diimplementasikan menggunakan pemrograman terstruktur karena pemrograman terstruktur membagi-bagi bagiannya dengan fungsi-fungsi dan prosedur.

\section{PERANCANGAN SISTEM}

\section{A. Tahapan Perancangan Sistem}

Model yang digunakan dalam penelitian tugas akhir ini adalah model waterfall. Model waterfall terdiri dari 5 tahap yaitu Analisis Kebutuhan, Desain, Pengodean, Pengujian dan Pemeliharaan.

\section{B. Analisis Kebutuhan}

Tahapan analisis kebutuhan dilakukan untuk menspesifikasikan kebutuhan perangkat lunak agar dapat dipahami perangkat seperti apa yang diinginkan user dan kemudian mentransformasikan ke dalam sebuah deskripsi yang jelas dan lengkap.

1. Kebutuhan Pengguna

Setelah mendeskripsikan tahapan kerja dan disertai informasi serta kendala yang ada, didapatkan kebutuhan untuk kemudahan memanajemen data. Kebutuhan tersebut adalah :

1. Adanya fasilitas pembagian user yaitu Admin, dan Visitor.

2. Adanya login untuk admin untuk dapat mengakses database pada sistem.

3. Adanya fasilitas admin untuk menambah,mengubah,dan menghapus artikel.

4. Admin, dan Visitor dapat melihat objek 3d rumah adat pada website.

5. Adanya logout untuk admin untuk keluar dari sistem

2. Aktor yang Terlibat

Terdapat beberapa aktor yang terlibat dalam pembuatan aplikasi manajemen ini, yaitu :

1. Admin

Admin merupakan pengguna yang memiliki otoritas untuk mengakses semua fasilitas yang tersedia pada sistem. Admin dapat mengelola semua informasi yang ada pada sistem.

2. Visitor

Visitor merupakan pengguna yang hanya dapat melihat informasi yang ditampilkan oleh 
sistem. Visitor tidak memiliki otoritas untuk mengelola informasi yang ada pada website.

\section{Desain}

Tahap perancangan / desain perangkat lunak merupakan proses multi langkah dan berfokus pada beberapa atribut perangkat lunak. Proses ini berdasarkan dari analisa sebelumnya sehingga menciptakan sebuah rancangan yang sesuai dengan kebutuhan dari pihak terkait. Dalam perancangan perangkat lunak ini, digunakan Entity Relationship Diagram (ERD) untuk pemodelan basis data dan UML untuk pemodelan perangkat lunak.

1. ERD

Entity Relationship Diagram (ERD) adalah salah satu metode pemodelan data yang digunakan untuk menggambarkan suatu basis data.

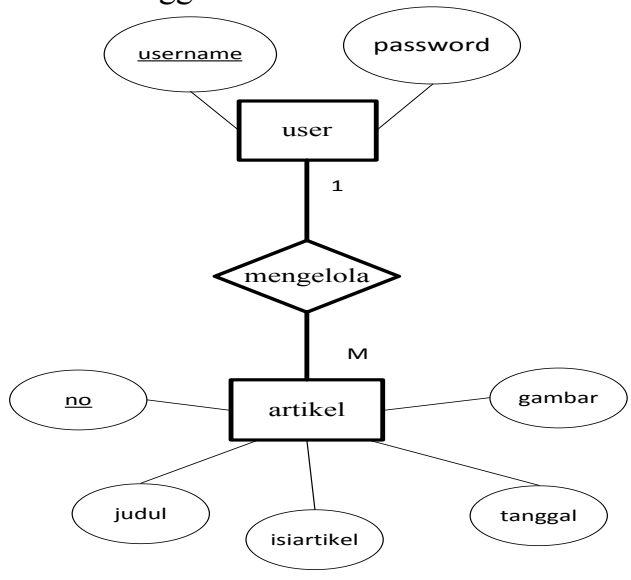

Gambar 1 ERD aplikasi

2. DFD (Data Flow Diagram)

a. DFD Level 0 (Diagram Konteks)

DFD level 0 ini menggambarkan interaksi antara sistem yang akan dikembangkan dengan entitas luar

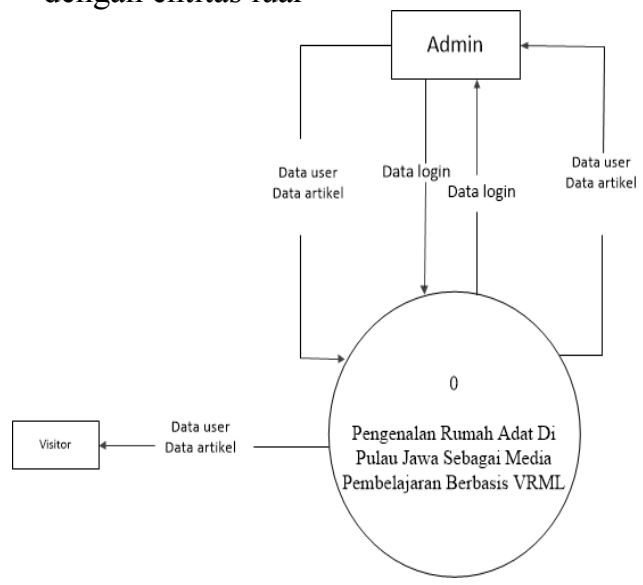

Gambar 2 Diagram Konteks b. DFD Level 1

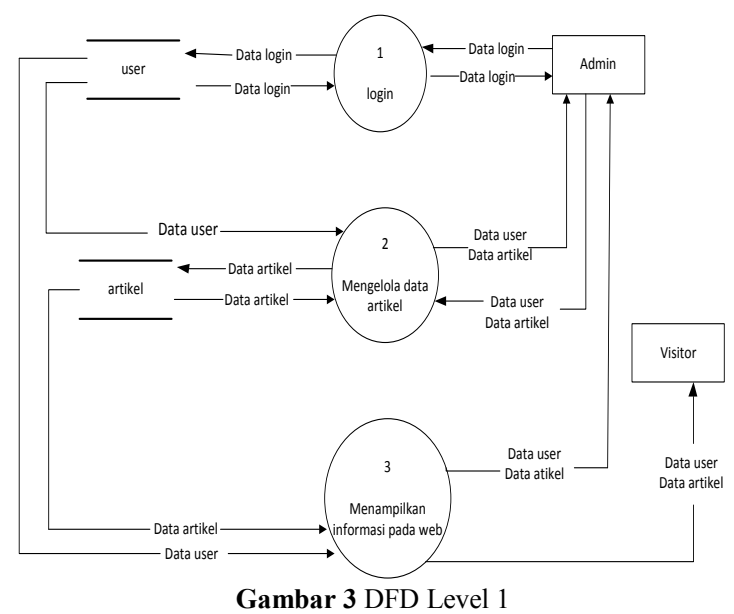

c. DFD Level 2 Mebgelola Artikel

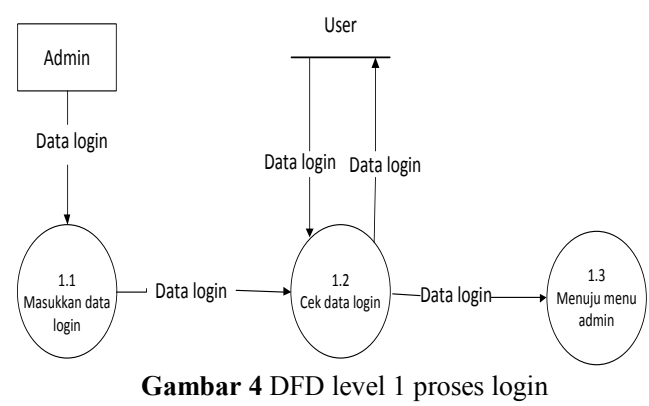

d. DFD Level 2 Mengelola Artikel

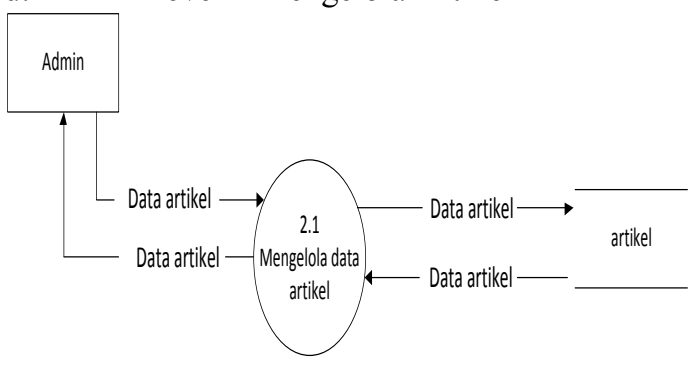

. Gambar 5 DFD level 2 mengelola artikel

e. DFD Level 3 Mengelola Artikel

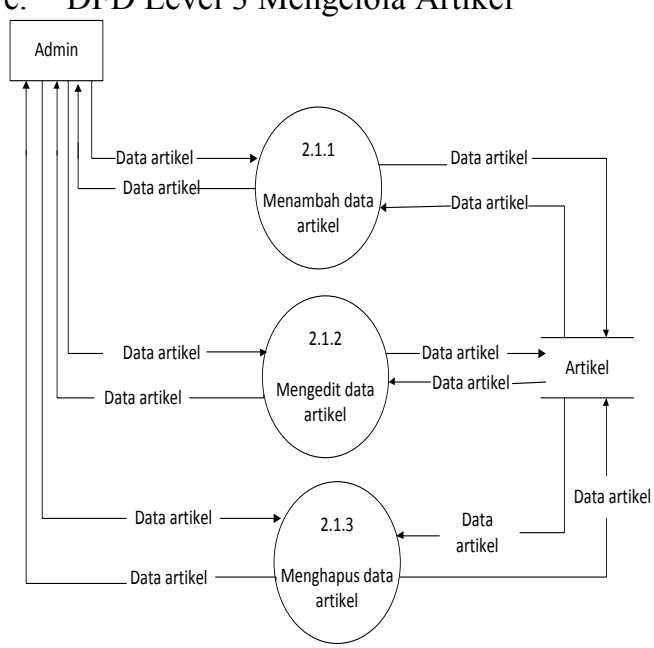

Gambar 6 DFD level 3 mengelola arikel 
3. Flowchart Aplikasi

Flowchart adalah diagram yang menggambarkan secara mendetail urutanurutan proses dan hubungan antar satu proses dengan proses lainnya dalam suatu sistem dengan menggunakan simbol-simbol. Berikut merupakan flowchart aplikasi.

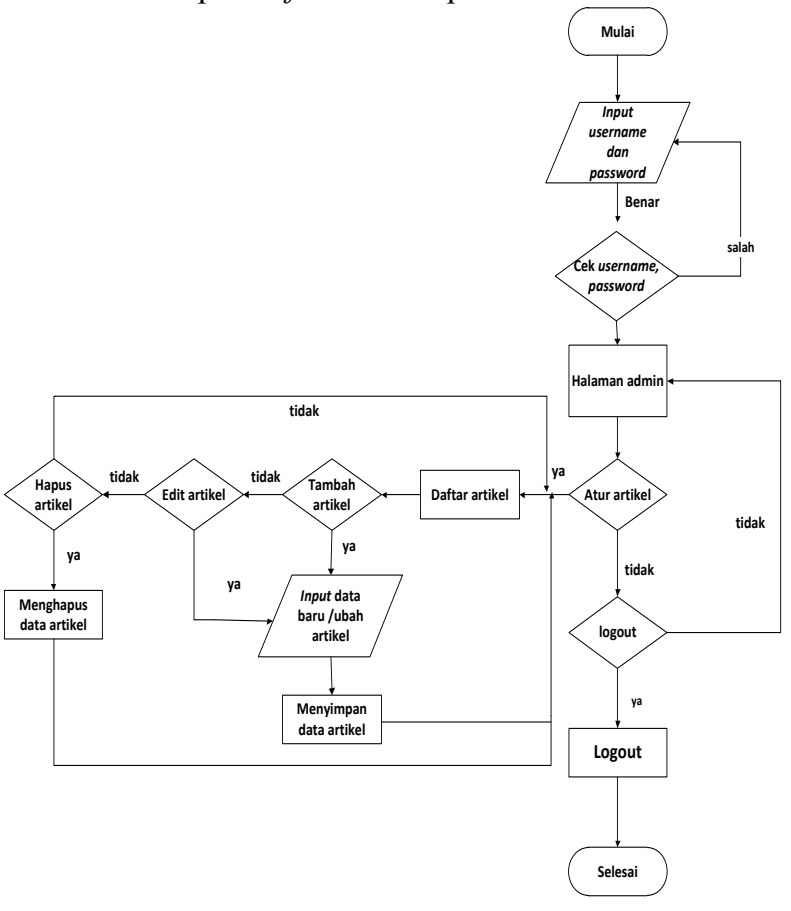

Gambar 7 Flowchart Aplikasi

4. Perancangan Antarmuka

Bagian - bagian yang berhubungan langsung dengan pengguna aplikasi disebut antarmuka / interface. Perancangan antarmuka aplikasi sangat dibutuhkan agar aplikasi dapat dioptimalkan kemudahan pengoperasiannya ketika digunakan oleh pengguna (userfriendly).

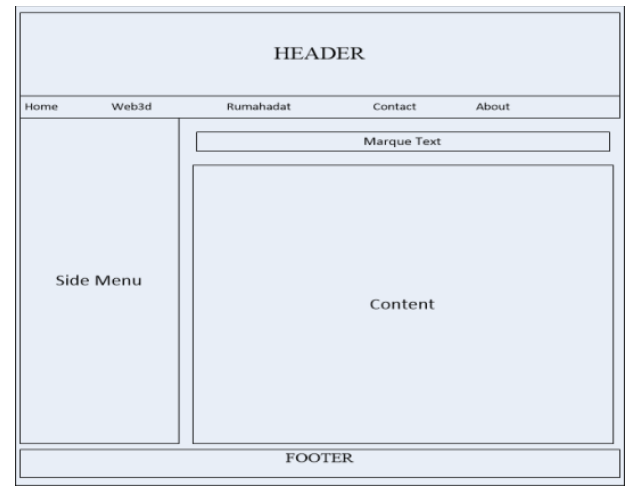

Gambar 8 Desain halaman awal web

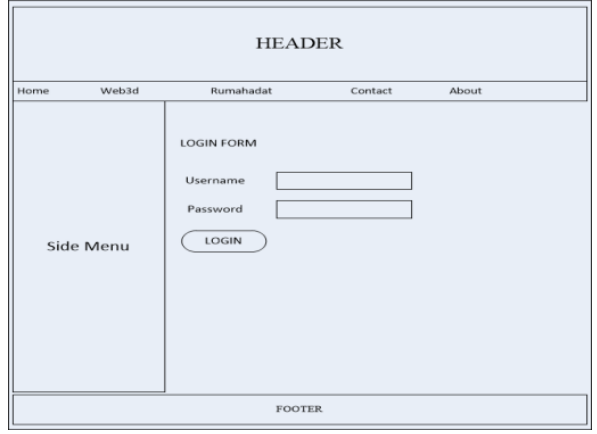

Gambar 9 Desain Halaman Login

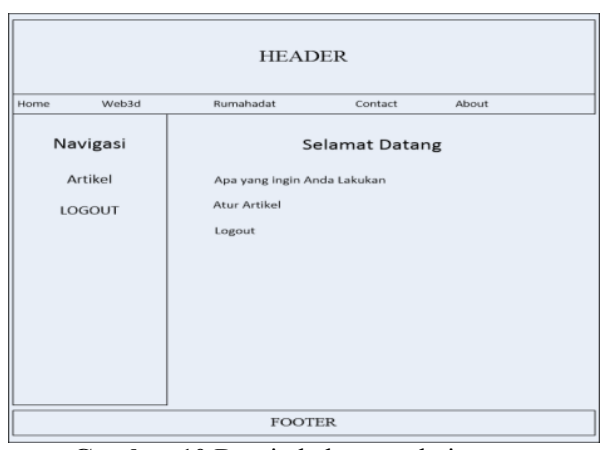

Gambar 10 Desain halaman admin

\section{IMPLEMENTASI DAN PENGUJIAN}

\section{A. Implementasi Basis Data}

Tahapan ini mengimplementasikan hasil perancangan basis pada sistem yang telah dibuat sebelumnya. Gambar 11 menunjukkan implementasi basis data pada aplikasi.

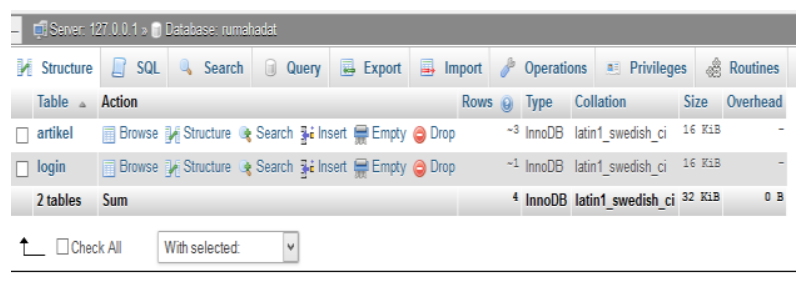

Gambar 11 Implementasi basis data

Gambar 12 menunjukkan tentang implementasi tabel login dan gambar 13 menunjukkan implementasi tabel artikel.

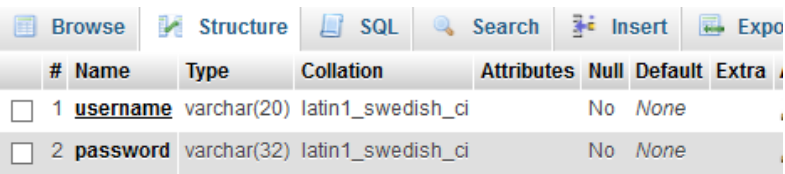

Gambar 12 Implementasi tabel login

\begin{tabular}{|c|c|c|c|c|c|c|c|}
\hline & \# Name & Type & Collation & Attributes & Null & Default & Extra \\
\hline ב & $1 \underline{\text { no }}$ & $\operatorname{int}(3)$ & & & No & None & AUTO_INCREMENT \\
\hline ] & 2 judul & $\operatorname{varchar}(50)$ & latin1_swedish_ci & & No & None & \\
\hline & 3 isiartikel & text & latin1_swedish_ci & & No & None & \\
\hline & 4 tanggal & date & & & No & None & \\
\hline & 5 gambar & $\operatorname{varchar}(100)$ & latin1_swedish_ci & & No & None & \\
\hline
\end{tabular}

Gambar 13 Implementasi tabel artikel 


\section{B. Implementasi Antarmuka}

Berikut ini merupakan antarmuka yang dimiliki Aplikasi Pengenalan Rumah Adat di Pulau Jawa Sebagai Media Pembelajaran Berbasis VRML

1. Halaman Utama

Berisi tentang halaman awal ketika web diakses oleh para pengunjung.

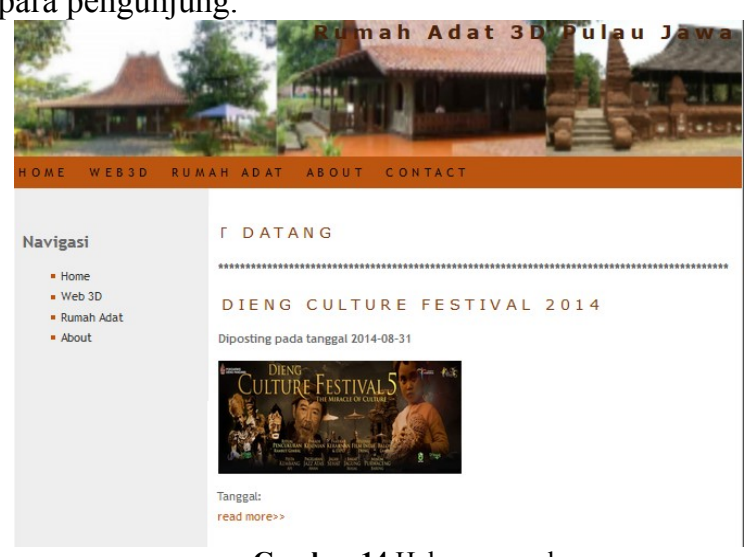

Gambar 14 Halaman awal

2. Halaman login

Berisi halaman untuk admin masuk ke sistem.

HOME WEB3D RUMAH ADAT ABOUT CONTACT

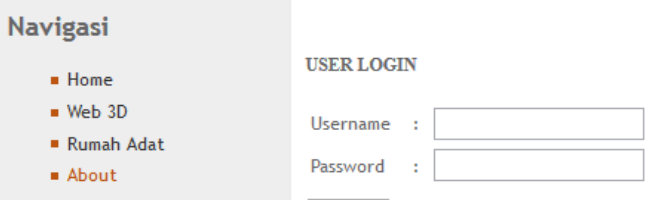

Login

Gambar 15 Halaman login

3. Halaman Admin

Berisi tentang admin dan kewenangan yang dapat dilakukan admin.

\begin{tabular}{|l|l|}
\hline HOME WEB 3D & RUMAH ADAT ABOUT CONTACT \\
\hline Navigasi & SELAMAT DATANG \\
" Artikel & Apa yang ingin Anda Lakukan? \\
" Logout & Pengaturan Artikel \\
& logout \\
\hline
\end{tabular}

Gambar 16 Halaman admin

4. Halaman Pengaturan Artikel

Berfungsi untuk mengatur artikel yang terdapat pada website.

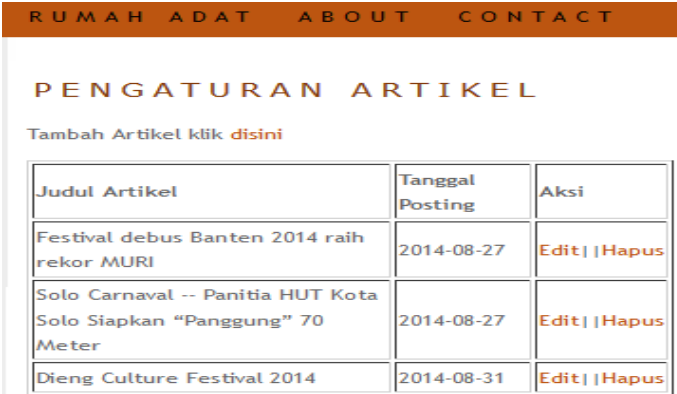

Gambar 17 Halaman pengaturan artikel

5. Halaman Rumah adat 3D

Halaman ini menampilkan tampilan rumah adat secara 3D melalui plugin cortona3dviewer. Dihalaman ini pengunjung dapat melihat rumah adat $3 \mathrm{D}$ sesuai provinsi yang dipilih.
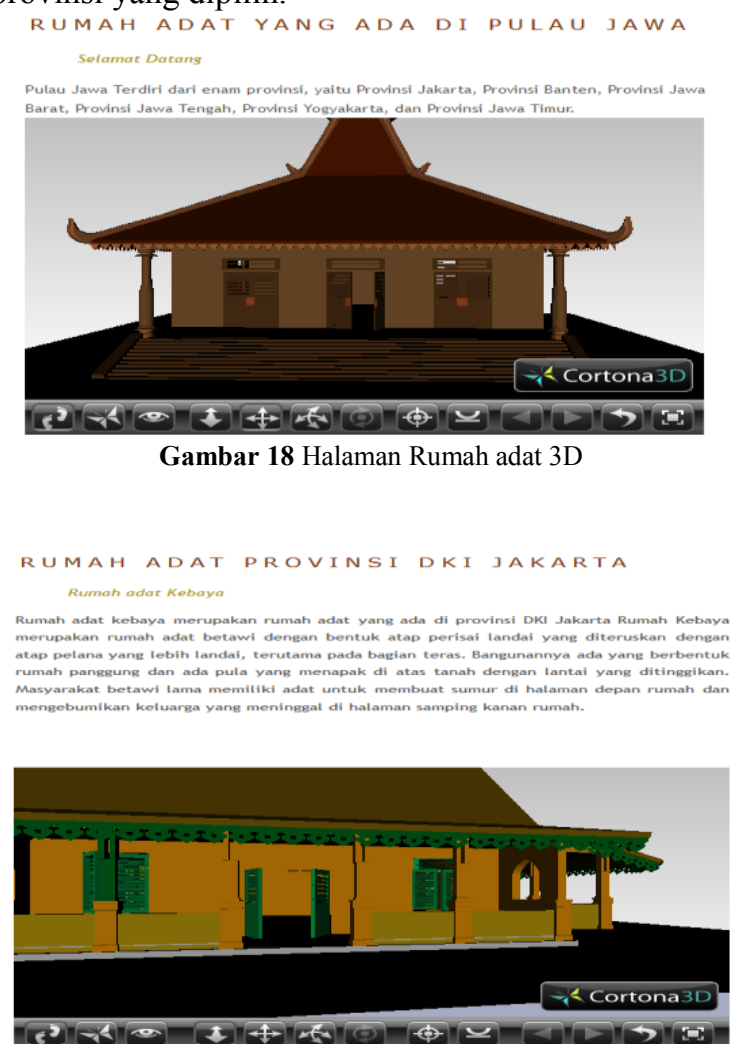

Gambar 19 Halaman Rumah adat 3D provinsi DKI Jakarta

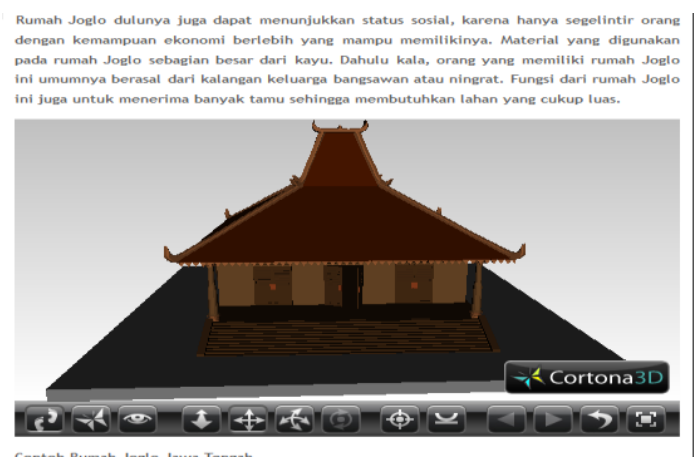

Gambar 20 Halaman Rumah adat 3D provinsi Jawa Tengah 
6. Halaman Lihat Per Artikel

Halaman ini menampilkan artikel yang ingin dibaca oleh para pengunjung secara penuh setelah sebelumnya pengunjung menekan "read more" pada artikel yang ingin dibaca

DIENG CULTURE FESTIVAL 2014
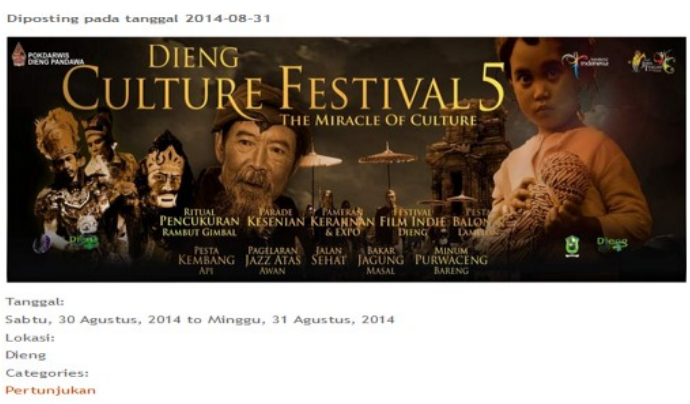

Gambar 21 Halaman lihat per atikel

\section{Halaman About}

Halaman about menunjukkan tentang aplikasi rumah adat di pulau Jawa sebagai media pembelajaran berbasis VRML.

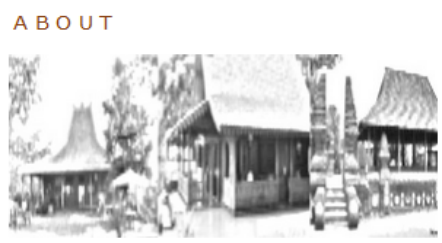

Website Rumah adat di Pulau Jawa 3D berbasis VRML dibuat untuk memberikan

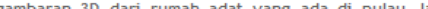
adat yang ada pada website ini. Rumah adat 3d bibangun dengan teknologi VRML. Diharapkan dengan adanya teknologi VRML ini pengunjung dapat dengan mudah nenikamati rumah adat yang ada di pulau Jawa secara lebih interakti.

Gambar 22 Halaman About

\section{Pengujian}

Proses pengujian dilakukan menggunakan metode white box. Pengujian white box (glass box) adalah pengujian yang didasarkan pada pengecekan terhadap detail perancangan, menggunakan struktur kontrol dari desain program secara prosedural untuk membagi pengujian ke dalam beberapa kasus pengujian.

Tabel-tabel di bawah ini merupakan ringkasan dari pengujian yang telah dilakukan. Pertama adalah Tabel 1 yang merupakan ringkasan pengujian yang berhubungan dengan pengelolaan data User.

Metode pengujian basis path yang merupakan salah satu metode pengujian white box. Teknik uji coba untuk mengukur kompleksitas logis dari desain prosedural dan menggunakannya sebagai pedoman untuk menetapkan himpunan basis dari semua jalur eksekusi. Tahapan pengujian basis path meliputi:

1. Mendefinisikan node - node dari kode program

$=\mathrm{Simpul} /$ node, merepresentasikan satu atau lebih statement procedural

$\longrightarrow=$ link/edge, merepresentasikan aliran kontrol. Setiap node harus mempunyai tujuan node.
$\mathrm{R}=$ Area yang dibatasi node dan edge disebut region dan untuk menghitung region, daerah diluar flowgraph juga harus dihitung.

2. Membuat grafik alir (flowgraph)

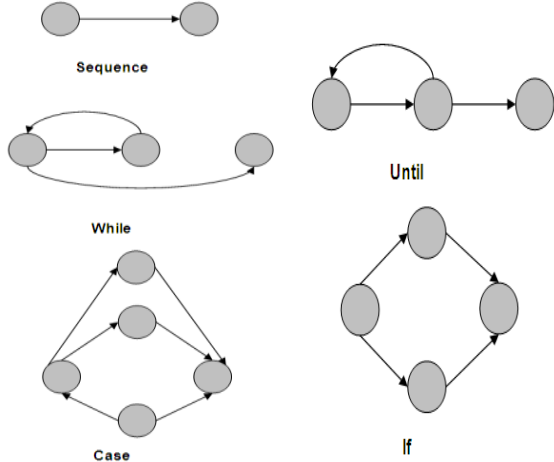

Gambar 23 Contoh penulisan flowgraph

3. Menentukan kompleksitas siklomatis dari grafik alir

Menentukan jalur independen menggunakan metrik Kompleksitas Siklomatis menggunakan rumus:

$\mathrm{V}(\mathrm{G})=\mathrm{E}-\mathrm{N}+2$

$\mathrm{V}(\mathrm{G})=\sum \mathrm{R}$

dimana $\mathrm{E}=$ jumlah edge

$\mathrm{N}=$ jumlah node

$\sum \mathrm{R}=$ jumlah region

4. Menentukan jalur independen berdasarkan nilai kompleksitas siklomatis.

5. Melakukan pengujian berdasarkan jalur independen yang didapat.

1. Pengujian Login

Tahapan pertama yaitu mendefinisikan node node dari kode program.

-node1- <?php

-node2- if (isset (\$_POST['login']) and

\$ POST['login']=="login") \{include "konek.php"

-node3- \$pass=MD5 (\$ POST ['password']) :

-node3- \$name= HTMLENTITIES (\$_POST [' username'], ENT_QUOTES) -node3- \$login=mysql_query ("select * from login

There username $=1 "$.\$name. " ' and password $=$ " "\$pass." '") -node3- \$ketemu=mysq1_num_rows (\$login);

-node4- if (\$ketemu $\overline{>} 0)$

-node5- \$r=mysql fetch array (\$login);

-node6- session start():

-node6- \&SESSION [ ' log'] = true;

-node6- \$_SESSION[' username'] =\$r['username '];

-node6- \$ SESSION ['username'] =\$r['password '];

-node7- header ('location:admin.php');

-nodes- $\}$ else

header ("location:login.php?view=gagal")

\}

-node9- ?>

Tahapan kedua yaitu membuat flowgraph berdasarkan edge dan node pada tahapan pertama. 


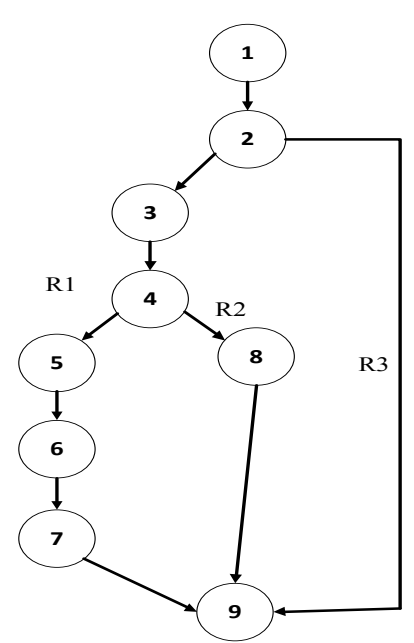

Gambar 24 Tampilan flowgraph login

Tahapan ketiga yaitu menentukan kompleksitas siklomatik dari tahap kedua

Penentuan komplesitas siklomatik dari grafik alir digunakan rumus:

$\mathrm{V}(\mathrm{G})=\mathrm{E}($ edges $)-\mathrm{N}($ nodes $)+2$

$\mathrm{V}(\mathrm{G})=\sum \mathrm{R}$ (jumlah region)

Dari grafik alir pada gambar 24 dapat ditentukan kompleksitas siklomatik sebagai berikut:

$\mathrm{V}(\mathrm{G})=10-9+2=3$

$\mathrm{V}(\mathrm{G})=3$ (jumlah region adalah tiga)

Kompleksitas Siklomatis yaitu : R1,R2,R3

Tahapan keempat yaitu menentukan jalur independen berdasarkan nilai kompleksitas siklomatis

Jalur $1(\mathrm{R} 1)=1-2-3-4-5-6-7-9$

Jalur $2(\mathrm{R} 2)=1-2-3-4-8-9$

Jalur $3(\mathrm{R} 3)=1-2-9$

Tahapan kelima yaitu melakukan pengujianpada masing - masing jalur independen .

Tabel 1 Pengujian login
\begin{tabular}{|c|c|l|l|}
\hline Jalur & Pengujian & $\begin{array}{l}\text { Hasil yang } \\
\text { diharapkan }\end{array}$ & $\begin{array}{l}\text { Hasil } \\
\text { yang } \\
\text { diperoleh }\end{array}$ \\
\hline 1 & $\begin{array}{l}\text { Masukan } \\
\text { form login } \\
\text { benar }\end{array}$ & $\begin{array}{l}\text { Menuju ke } \\
\text { halaman } \\
\text { admin }\end{array}$ & $\begin{array}{l}\text { Menuju } \\
\text { ke } \\
\text { halaman } \\
\text { admin }\end{array}$ \\
\hline 2 & $\begin{array}{l}\text { Masukan } \\
\text { form login } \\
\text { salah }\end{array}$ & $\begin{array}{l}\text { Kembali ke } \\
\text { halaman } \\
\text { login }\end{array}$ & $\begin{array}{l}\text { Kembali } \\
\text { ke } \\
\text { halaman } \\
\text { login }\end{array}$ \\
\hline 3 & $\begin{array}{l}\text { Form } \\
\text { login tidak } \\
\text { diisi }\end{array}$ & $\begin{array}{l}\text { Kembali ke } \\
\text { halaman } \\
\text { login }\end{array}$ & $\begin{array}{l}\text { Kembali } \\
\text { ke } \\
\text { halaman } \\
\text { login }\end{array}$ \\
\hline
\end{tabular}

\section{PENUTUP}

\section{A. Kesimpulan}

Berdasarkan hasil pengujian dan analisis aplikasi pengenalan rumah adat di pulau Jawa sebagai media pembelajaran berbasis VRML, maka dapat disimpulkan beberapa hal sebagai berikut.

1. Teknologi VRML dapat diimplementasikan dalam pembuatan objek 3D rumah adat agar mendukung aplikasi interaktif berbasis web untuk media pembelajaran.

2. Penggunaan tampilan $3 \mathrm{D}$ rumah adat membuat pengguna dapat berinteraksi dengan objek 3D rumah adat, seperti menggerakkan objek 3D rumah adat untuk melihat rumah dari segala sisi,

3. Aplikasi pengenalan rumah adat di pulau Jawa ini dapat berjalan sesuai dengan skenario sistem yang telah dirancang

4. Pengujian White Box berfungsi untuk menguji kesalahan logika - logika dan fungsi - fungsi dalam suatu sistem.

5. Pengujian menggunakan sql injection pada form login gagal menunjukkan sistem telah kebal dari serangan sql injection pada form login.

\section{B. Saran}

Berdasarkan hasil pengujian dan analisis pengenalan rumah adat di pulau Jawa sebagai media pembelajaran berbasis VRML, dapat diberikan beberapa saran sebagai berikut.

1. Aplikasi VRML yang dikembangkan dapat menampilkan objek 3D rumah adat seluruh provinsi yang ada di Indonesia.

2. Aplikasi VRML yang dikembangkan dapat menampilkan objek 3D rumah adat secara lebih mendetail.

3. Pengembang disarankan dapat mengembangkan aplikasi pengenalan rumah adat ini agar dapat dijalankan pada perangkat bergerak (mobile device).

\section{DAFTAR PUSTAKA}

[1] A.S., R., \& Shalahuddin, M. (2013). Rekayasa Perangkat Lunak Terstruktur dan Berorientasi Objek. Bandung: Informatika.

[2] Anwar, B. (1999a). Belajar Sendiri Bahasa Pemrograman VRML 1.0. Jakarta: PT Elex Media Komputindo.

[3] Anwar, B. (1999b). Belajar Sendiri Bahasa Permrograman VRML 97. Jakarta: PT Elex Media Komputindo.

[4] Bell, Douglas.(2005). Software Engineering for Students A Programming Approach 4th Edition. England : Pearson Education Limited.

[5] Coltekin, A., Heikkinen, J., \& Ronnholm, P. (2003). Studying Geometry, Color, and Texture in VRML. Helsinki: Institute of Photogrammetry 
and Remote Sensing, Helsinki University of Technology.

[6] Fadillah, M. H. (2011). Implementasi VRML pada Media Pembelajaran Geometri untuk Sekolah Dasar dengan Menggunakan Metode Pembentukan Objek Ekstrusi. Institut Pertanian Bogor.

[7] Hakim, Lukmanul. (2011). Membongkar Trik Rahasia Para Master PHP. Yogyakarta:Lokomedia

[8] Kadir, A. (2009a). From Zero to a Pro Membuat Aplikasi Web dengan PHP dan Database MySQL. Yogyakarta: Andi Offset.

[9] Kadir, A. (2009b). Mastering AJAX dan PHP. Yogyakarta: Andi Offset.

[10] Khan. Mohd.Ehmer.(2011) Different Approaches to White Box Testing Technique for Finding Errors. Department of Information Technology Al Musanna College of Technology, Sultanate of Oman
[11] Kurniadi, A. (1999). Membuat Dunia 3D dengan VRML. Jakarta: PT Elex Media Komputindo.

[12] Nugroho, Bunafit. (2008). Latihan Membuat Aplikasi Web PHP dan MySQL dengan Dreamweaver. Yogyakarta: Gaya Media.

[13] Raharjo, B., Heryanto, I., \& Enjang, R. (2012). Modul Pemrograman Web HTML, PHP, dan MySQL (Revisi.). Bandung: Modula.

[14] Taylor.A.David .(1992). Object-Oriented Information System Planning and Implementation.USA: Wiley \& Sons Inc.

[15] Wahyono, T. (2009). Practice Guide PHP On Windows. Jakarta: PT Elex Media Komputindo. 